\title{
DIAPAUSE IN THE BEET WEBWORM
}

\author{
L. G. PUTNAM, 35 Kirk Crescent, Saskatoon, Saskatchewan. S7H 3B1
}

A leaf-eating insect species that lives all year in Saskatchewan must not only be able to avoid freezing to death, but must avoid hatching or otherwise emerging into an environment in which the food supply is deteriorating and the cold temperatures of winter rapidly approaching. The physiological state that preserves such a species in a state of arrested development through the winter, so that it can resume its life processes when the environment is improving, not worsening, is called diapause. This condition corresponds to dormancy in plants. Some period of experience at winter temperatures is required to "break diapause" and permit the resumption of development. For example, in one of our pest grasshoppers, the Clear-winged Grasshopper (Camnula pellucida Scud.), diapause intervenes when the embryo in the egg has undergone about half its progress toward readiness to hatch. No matter how much warm weather the egg experiences in the late summer and fall, nothing happens beyond the halfway stage until spring. In the Bertha Armyworm, diapause occurs in the pupal stage; the pupa, formed in the fall, remains secure in the soil until spring. In other species, diapause may occur in a larval stage, in nymphs, or even in adults that winter over; in the latter case, a reproductive diapause may occur in a larval stage, in nymphs, or even in adults that winter over; in the latter case, a reproductive diapause delays sexual maturity until spring. Our pest fleabeetles are an example of the latter kind.

In this article, I wish to enlarge a little on the diapause situation in the Beet Webworm, Loxostege sticticalis L.
(Lepidoptera: Family Pyralidae). In the past, this species has been a pest, its marching habit resulting in invasions of broadleaved horticultural and field crops. For its food supply, especially at the "nursing" stage, this species favours plant species of the goose-foot family (Chenopodiaceae), notably Sugar Beets, Lambs' Quarters and, surprisingly, Russian Thistle. Completing its larval growth, the Beet Webworm burrows into the soil and spins a cocoon about $3 \mathrm{~cm}$ long. When the caterpillars have been abundant, it is easy to sift these cocoons out of soft earth or sandy ridges along the edges of fields containing suitable food plants. The larva within the cocoon may soon enter the pupal stage, followed by the adult moth without interruption, or, it may remain in the larval or "prepupal" stage until the following spring. Thus the species is potentially capable of two things: producing more than one generation in one growing season, and saving enough over winter to get the population going the following year. Two generations a year have been claimed for Montana, and more for the warmer parts of Asiatic Soviet Union. I wish to elaborate on this "facultative diapause" situation.

It turns out that the beet webworm is an example of those species in which the occurrence of diapause is determined by day length (hours of light/ day) and temperature experienced by the insect during its larval stage. Logically enough, short day length and cool temperatures, indicative of approaching winter, tend to put the spun-up caterpillar in diapause, and the opposite conditions tend to reduce 
or entirely avert it. Danilevskii compiled the information on day length and diapause in numerous species in a book published in $1965 .{ }^{1}$ Some data from experiements performed by myself show how temperature and photoperiod interact to affect diapause in the beet webworm.

No beet webworm caterpillars reared under 17 hours of light per day entered diapause after rearing at any constant temperature from 19 to $27^{\circ} \mathrm{C}$. At 15.5 hr, only 5 to $20 \%$ did so at any of those temperatures. We were normally able to keep a culture going generation after generation in the greenhouse without interruption due to diapause with a day length of $16 \mathrm{hr}$, given any temperature favourable for insect and food plant development, 'round the clock. At $14 \mathrm{hr}$ light per day, response to controlled rearing temperatures became quite sensitive. At an approximately constant temperature of 19$20^{\circ} \mathrm{C}$, nearly $100 \%$ entered diapause at $14 \mathrm{hr}$, but at $25-26^{\circ}$, only $45 \%$ did. At the very warm constant temperature of $35^{\circ}$, only $20 \%$ diapaused even at the brief day length of $12 \mathrm{hr}$. Thus what is for us an unrealistically high temperature can negate the expected effects of short day length.

Constant temperatures applied to caterpillars feeding actively on foliage in the rearing chamber are of course unrepresentative of what occurs in the field, where it is often difficult to be sure of what the thermal experience of an insect is. In the laboratory, we were able to impose fluctuating temperature regimes with a daily range of 9 to $20^{\circ} \mathrm{C}$, and of 10 to $26^{\circ}$. With a photoperiod about typical of June to early August at latitude $52^{\circ} \mathrm{N}$, the response was quite sensitive to these different programs: high percentage diapause to the cooler one, and low from the warmer. There would thus seem to be a possibility for differing diapause response under natural conditions, depending on the thermal experience of a larval brood, whether at different times of the same year, or at the same times in different years. For example, if the main larval brood occurred late in summer, or if there were two broods, one early and one late, the late broods might respond differently from the earlier one.

In a field cage experiment performed in 1969, larvae developing from 3 June to 15 July (photographed about 16.5 $\mathrm{hr}$ ), diapause incidence was about $38 \%$; from 4 July to 7 August (photoperiod declining from 16.5 to $15.1 \mathrm{hr}$ ), 53\%; and from 12 August to 7 September (photoperiod declining from 14.8 to $13.25 \mathrm{hr}$ ), $98 \%$. The temperatures were those occurring naturally: the average daily mean temperature at Saskatoon for the first period was $14.5^{\circ} \mathrm{C}$, about $1.8^{\circ}$ below normal; for the second, 17.6 , also about $1.8^{\circ}$ below normal; and for the third, $17.6^{\circ}$, about $1.2^{\circ}$ above normal. Photoperiod seems to contribute more to understanding the results than temperatures in this case.

During these investigations, only three collections of maturing larvae were taken from the field to determine diapause on final rearing in the laboratory. All were collected early in August of different years, having completed most of their development in July. In each, 60 to $65 \%$ of the larvae entered diapause in the cocoons.

Both the field cage work and the samples from field infestations were too limited to encompass all the possibilities, but the indications are that under most conditions in the field, at times under which a larval brood is likely to develop, half or more would enter diapause. Any that did not do so, and that emerged as moths in August or later the same year, would produce progeny that would have a doubtful future. It remains to be seen whether some conditions in the field would be 
extreme enough to result in negligible diapause, with a corresponding failure of the overwintering population attended by a crash next year, or conversely, whether an unusually high percentage might enter diapause, with a heavy moth flight the following year.

The experiments reported here were performed while the author was em- ployed at the Canada Agriculture Research Station, 107 Science Crescent, Saskatoon, Saskatchewan. S7N $0 \times 2$, using the Station's laboratory and greenhouse facilities.

'DANILEVSKII, A.S. 1965. Photoperiodism and seasonal development of insects. Oliver and Boyd. 283 pp ix.

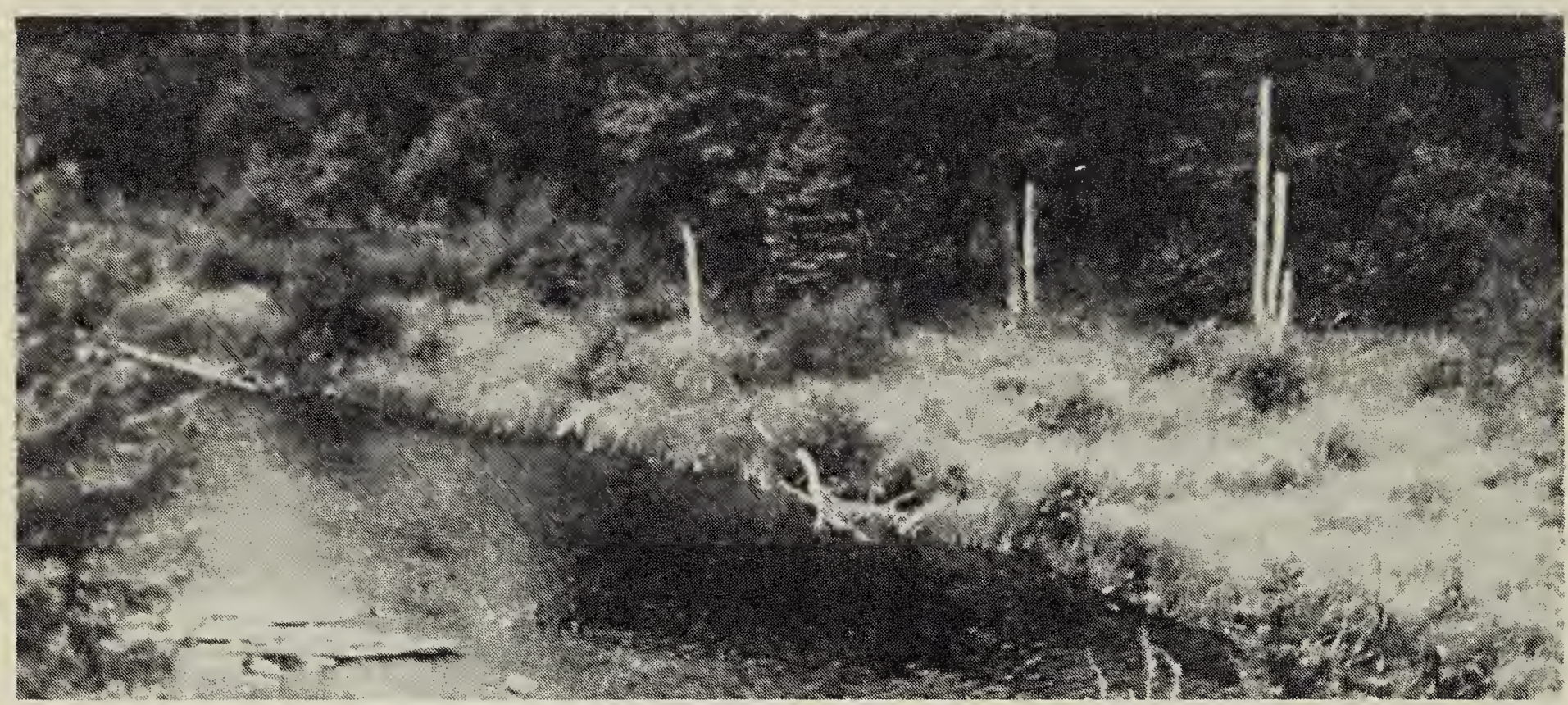

MacLennan River, Prince Albert National Park

Blake Maybank

\section{OF ICE WORMS AND SNOW FLEAS}

ALAN R. SMITH and A. LINDA LAHEY, 614 Lansdowne Avenue, Saskatoon. S7N $1 E 3$

On 13 March 1983, a warm springlike day in northern Saskatchewan, we were walking down the trail to Trappers Lake in Prince Albert National Park when we noticed that the snow was covered with what appeared to be soot. A closer examination revealed the prescence of millions of tiny insects. At that time the only thing we knew about them was that they were called "snow fleas".

The thought that cold-blooded animals of any kind can tolerate or even thrive in the snow is bound to cause scepticism. But "ice worms" and "snow fleas" do exist. Ice worms are oligochaete worms that actually live and breed in the snow of glaciers. Snow fleas are members of the insect order Collembola which are familiarly known as springtails. The most commonly-occurring snow flea is Achorutes nivicolis (Fitch); it is this species that we believe we saw at Trappers Lake on this day and two weeks later on 27 March. 